\title{
"A Retrospective Study of Correlation Between Reported Dose Volume Parameters For Urinary Bladder, Rectum \& Sigmoid Colon With Clinical Outcome In High Dose Rate Brachytherapy of Carcinoma Cervix"
}

\author{
${ }^{1}$ Dr. Kazi S. Manir, M.D., DNB, ${ }^{2}$ Dr. Niladri B. Patra M. D., \\ ${ }^{3}$ Dr. Anindya Mukherjee, M.D., DNB, ${ }^{4}$ Dr. Swapnendu Basu, M.D., DNB, \\ ${ }^{5}$ Prof. Shyamal K. Sarkar, Dip Card, D.T.M.H., M.D., \\ ${ }^{6}$ Mr. Jayanta K. Pal, M Sc, Dip R.P \\ ${ }^{I}$ RMO Cum Clinical Tutor, Department Of Radiotherapy, R.G.Kar Medical College \& Hosptial, Kolkata, India \\ ${ }^{2}$ Associate Professor Department Of Radiotherapy, Medinipore Medical College \& Hospital, Medinipore, WB, \\ India \\ ${ }^{3}$ Senior Resident, Department Of Radiotherapy, PGIMER, Chandigarh, India \\ ${ }^{4}$ Consultant Radiation Oncologist, Medica Cancer Hospital, Siliguri, WB, India \\ ${ }^{5}$ Professor And Head Department Of Radiotherapy,Medical College And Hospitals, Kolkata, India \\ ${ }^{6}$ Medical Physicist Department Of Radiotherapy, Medical College And Hospitals, Kolkata, India
}

\section{Introduction}

Today point-based two-dimensional Brachytherapy (BT) is most often used for definitive radiotherapy in cervical cancer ${ }^{[1]}$. Results of Computer tomography (CT)/Magnetic Resonance Imaging (MRI) guided 3Dimensional brachytherapy are very promising and paving the way to image based Brachytherapy. Feasibility to conform dose in image based BT allowed clinicians to adapt dose distribution in organs at risk and tumor in each fraction. Centers practicing image based BT showed improved dose distribution and outcome and decreased morbidity ${ }^{[1]}$.

The GEC-ESTRO working group published recommendations for reporting target delineation and DVH parameters in MRI-based cervix cancer Brachytherapy ${ }^{[2,3]}$. According to available literature ${ }^{[4,5 \text { and } 6]}$, reporting of small volume high dose regions for OAR is recommended. $D_{2 c c}, D_{1 c c}$ and $D_{0.1 c c}$ of any OAR are defined as the minimum doses to the most exposed 2, 1 and $0.1 \mathrm{cc}$ of the respective OAR.

Late side effects in rectum and urinary bladder have always been a major concern in ICBT ${ }^{[7-16]}$. Till now there is limited data available to correlate clinical outcome with reported doses in image based ICBT and there is no consensus regarding which dose volumes are more important in predicting late toxicities ${ }^{[7-20]}$. Georg P et al. ${ }^{[17]}$ did a study to correlate dosimetric parameters for MRI based 3D planning with rectoscopic findings and clinical rectal side effects. In this study the locations of mucosal changes detected by rectosigmoidoscopy correlates to the MRI defined high dose volumes. The authors established a clear doseeffect and volume- effect relationship in clinic-pathological changes in rectum.

Recently, EMBRACE (An International study on MRI guided brachytherapy in locally advanced cervical cancer) ${ }^{[1]}$, a multi centric prospective study has been started from July 2008 to correlate MRI based DVH parameters for the clinical target volume and for organs at risk with outcome. Study has not completed yet.

Keeping these previous works in background this study aims to search for clinical correlations between reported dose volumes for High Dose Rate ICBT in carcinoma cervix and definite clinical toxicities.

Study

\section{Materials and methods}

At the study hospital during 2006-2010, 227 patients with cervix carcinomas FIGO Stages IB-IVA were treated with combined EBRT and CT based brachytherapy \pm concomitant chemotherapy. All patients were followed up periodically for response and toxicity assessments. Data from this patient pool was gathered retrospectively for assessment in this study. During follow-up, patients were evaluated for bladder, rectal/sigmoid colon morbidity. Recto-sigmoidoscopy and cystoscopy was not done routinely. It was only done if there was any reported history of rectal bleeding or hematuria. Written consent was obtained before the examination. Patients having age 18-70 years without any history of total hysterectomy and/or radiation therapy for any other reason were included in the study. 
Patients underwent EBRT with 50Gy in 25 fractions 5 days a week over 5 weeks in AP-PA technique with ${ }^{60} \mathrm{Co}$ machine (Theratron $780 \mathrm{C}$, Best Theratronics Ltd, Ottawa, Ontario, Canada) with or without concurrent chemotherapy( with Cisplatin $40 \mathrm{mg} / \mathrm{m}^{2}$ weekly). During Brachytherapy patients underwent catheterization followed by insertion of the intrauterine tandem (by Manchester or Fletcher Suite type applicator).The empty bladder was instilled with diluted contrast material to define the bladder wall just before taking CT images and the whole organ was delineated and planning was done (Brachyvision TPS, Eclipse, Varian Medical Systems, Palo Alto CA) on the reconstructed CT images. Rectum was defined from ano-rectal junction (levator ani muscle was used as anatomical surrogate for ano-rectal junction a to recto-sigmoid flexure).For defining sigmoid colon we used the protocol used by Georg $\mathrm{P}$ et al. ${ }^{[17]}$ i.e. from recto-sigmoid flexure to that part of sigmoid which was dislodged more than $2 \mathrm{~cm}$ from uterus or parametria. Point A left and right and ICRU bladder and rectal points were marked on the digitally reconstructed radiographs (DRR).

The prescription for HDR was found to be weekly: a) 7 Gy/\# X 3 fractions, b) 9 Gy/\# X 2, c) 8 Gy/\# X 3 and d) 6 Gy/\# X4 fractions to point A to get an EQD2 ( EBRT + HDR ICBT) of 80 Gy $(\alpha / \beta=10 \mathrm{~Gy})$. 3D manual optimization of the HDR plans was done to restrict the per-fraction $\mathrm{D}_{2 \mathrm{cc}}$ dose to the sigmoid, rectum and bladder, EQD2 (cumulative EBRT and all ICBT fraction doses) dose <75 Gy to the rectum and sigmoid colon and $<85$ Gy to the bladder $(\alpha / \beta=3 \mathrm{~Gy})^{[1,20]}$.

Different volume doses to bladder, rectal and sigmoid colon $(0.1 \mathrm{cc}$ and $2 \mathrm{cc})$ were noted. All the patient were then treated by the GammaMed plus HDR after loader machine (Varian Medical Systems, Palo Alto, CA) using ${ }^{192}$ Iridium.

\section{Follow-up}

Study subjects were followed up for late toxicities related to bladder, rectum and sigmoid colon if any every 3 monthly for first 2 years and 6 monthly thereafter.

\section{Late toxicity assessment:}

All patients were assessed upon taking history and clinical examinations. We assessed patients based on subjective complaints of the patient. Patients having late toxicities (any toxicity event occurring after 90 days from initial follow up) had undergone detailed clinical examinations and (after having consent) investigations (if needed).

Those patients having per rectal bleeding had undergone proctoscopy and or sigmoidoscopy. Patients having adverse events suggestive of cystitis or haematuria were undergone cystoscopy.

Following events were taken into consideration for toxicity analysis:

Rectal: Proctitis, Rectal pain, Rectal hemorrhage, Rectal ulceration, Rectal obstruction, Rectal perforation, Rectal fistula

Sigmoid colon: Colonic hemorrhage, Colonic ulceration, Colonic obstruction, Colonic fistula, Colonic perforation

Urinary tract: Hematuria, Cystitis

Common Terminology Criteria for Adverse Events version 4.02 (CTCAE v4) ${ }^{[21]}$ was used for scoring the toxicity. Each type of toxicity was graded from 0-5. Maximum score in any symptom in any of the follow up visit was considered as score for statistical analysis. Mucosal changes extending both in rectum and sigmoid colon in endoscopic findings were reported in both groups separately for statistical purpose.

\section{Statistical analysis}

$\mathrm{D}_{0.1 \mathrm{cc}}$ and $\mathrm{D}_{2 \mathrm{cc}}$ doses were calculated for the each of the organs (rectum, Sigmoid colon and Urinary bladder) adding EBRT and Brachytherapy doses (all fractions) considering $\alpha / \beta=3 \mathrm{~Gy}$. The mean values and standard deviation were reported for each dose volume parameters. For statistical analysis, Independent $t$ sample test (2-tailed) and Pearson correlation coefficient was calculated. $\mathrm{P}<0.05$ was considered as statistically significant value. Grade 1-2 were grouped as mild toxicity and grade 3 and above as severe toxicity. For doseeffect analyses, CTCAE grade $\geq 3$ was used as quantal endpoints. All calculations were performed with the International Business Machine Statistical Package for the Social Sciences software version 20 (IBM SPSS, IBM Corporation, USA). Probit regression analysis was performed assuming and analyzing two binary variables toxicity or no toxicity to find out ED50 and ED5 values. Probit analysis was restricted only to those dose parameters which were significantly correlated in baseline analysis. 


\section{Descriptive statistics}

\section{Results}

Descriptive analysis of all 227 patients is detailed in Table 1.In our study most common age group was 45-60years (56.3\%).Majority $(71.35 \%)$ of the patients were post-menopausal. Majority $(94.1 \%)$ were having squamous cell carcinoma. Majority patients presented with FIGO stage IIB (43.7\%) and Stage IIIB (32\%). Mean overall treatment time was $81 \pm 19$ days.7Gy/3\# (50.3\%) and 8Gy/3\# (19.8\%) were two most commonly used ICBT fractionations. In majority (67\%) of cases Manchester Type applicator was used. Mean Point A dose was $80.2 \pm 7.3 \mathrm{~Gy}$.

Mean doses of EDQD2 $\mathrm{D}_{0.1 \mathrm{cc}}$ and $\mathrm{D}_{2 \mathrm{cc}}$ of rectum, bladder and sigmoid colon were summarized in the Table 2 below along with EQD2 Rectal Point and Bladder point dose ( $D_{\text {ICRU RECTAL }}$ and $D_{\text {ICRU BLADDER }}$ respectively). Mean $\mathrm{D}_{2 \mathrm{cc}}$ \& $\mathrm{ICRU}$ point doses of rectum and bladder were not comparable.

\section{Follow up statistics}

Patients were followed up till February 2015. Average follow up time was 40 month 20 days. Patients having minimum 3 months follow up $(n=206)$ were taken for analysis. The rest $21(9.4 \%)$ patients out of the 227 were excluded from the study.

\section{Rectal toxicity}

Proctitis, rectal ulcer and rectal hemorrhage were most common toxicities noted in our study. Analysing the follow up data we found $16.02 \%(\mathrm{n}=33)$ patient had proctitis. CTCAE Grade 1, 2, 3 and 4 incidences were $2.04 \%(n=5), 10.2 \%(n=21), 2.9 \%(n=6)$ and $0.05 \%(n=1)$ respectively. $12.1 \%(n=25)$ patients had rectal pain, among them $2.9 \%(n=6)$ had Grade $1,5.8 \%(n=12)$ had Grade 2 and $3.3 \%(n=7)$ were Grade 3. 18.45\% $(\mathrm{n}=37)$ patients suffered rectal hemorrhage. Incidences of Grade 1,2,3,4 rectal bleeding were $3.9 \%(\mathrm{n}=8), 4.3 \%(\mathrm{n}=9) 6.8 \%(\mathrm{n}=14)$ and $3.3 \%(\mathrm{n}=7)$ respectively. All the patients of rectal bleeding underwent proctoscopy and sigmoidoscopy. Patients having endoscopic evidence of rectal ulcer were classified in rectal ulcer group and analyzed separately.13.1\% $(\mathrm{n}=27)$ had rectal ulcer. $2.9 \%(\mathrm{n}=6)$ had Grade $1,5.8 \%$ $(n=12)$ had Grade 2 and 3.9\% $(n=8)$ had Grade 3 toxicity. There was no Grade 4 toxicity. One patient of rectal ulcer died in subsequent follow up. This event was scored as Grade 5 toxicity $0.05 \%(\mathrm{n}=1)$. No episode of rectal obstruction, fisuta and perforation noted.

\section{Sigmoid colon toxicity}

Sigmoid colon ulcer and hemorrhage were two morbidity patterns noted in the follow up. Events like Colonic perforation, obstruction and fistula was not seen in this study. Colonic hemorrhage and ulceration were classified on the basis of sigmoidoscopic apperences.9.7 \% $(n=20)$ patients suffered from colonic hemorrhage. Among them incidences of Grade1, 2, 3 and 4 were $1.4 \%(n=3), 2.4 \%(n=5), 3.9 \%(n=8)$ and $1.9 \%(n=4)$ respectively.6.7\% $(n=14)$ patients were diagnosed to have sigmoid colon ulcer. $1.4 \%(n=3)$ were Grade 1 , $3.4 \%(n=7)$ were Grade 2 and $1.4 \%(n=4)$ had Grade 3 rectal ulcer. No patient had Grade 4 colonic ulcer.

\section{Urinary tract toxicity:}

Cystitis and hematuria were assessed for toxicity events if there was a positive history. Total $16.5 \%$ (n = 34) patients experienced cystitis during follow up period. $1.9 \%(\mathrm{n}=4)$ had Grade $1,13.1 \%(\mathrm{n}=27)$ had Grade 2 and $1.4 \%(n=3)$ had Grade 3 cystitis. $6.7 \%(n=14)$ patients experienced haematuria during follow up among which $2.9 \%(\mathrm{n}=6)$ had Grade 2 and 3.4\% $(\mathrm{n}=7)$ had Grade 3. No Grade 1 or Grade 4 haematuria was noted. One patient $(0.05 \%)$ in hematuria group died later on due to intractable episodes. It was noted as Grade 5.

\section{Dosimetry analysis:}

Independent $\mathrm{T}$ sample test ( 2 tailed) was also done to establish difference between Groups with severe toxicities (CTCAE Grade $\geq 3$ ) with mild toxicities (CTCAE Grade 1-2).

\section{Rectal toxicity}

For proctitis significant differences were found in case of $\mathrm{D}_{0.1 \mathrm{cc}}(110.3 \pm 16.9 \mathrm{~Gy} \& 89.9 \pm 17.5 \mathrm{~Gy}, \mathrm{P}=$ $0.003)$ and $\mathrm{D}_{2 \mathrm{cc}}$ doses $(85.4 \pm 7.5 \& 75.8 \pm 46.8 \mathrm{P}=0.037)$ of rectum. Dosimetric analysis also showed similar findings in case of Rectal haemorrhage $\left(\mathrm{D}_{0.1 \mathrm{cc}}: 106.1 \pm 13 \mathrm{~Gy} \& 89.1 \pm 17.6 \mathrm{~Gy}, \mathrm{P}=<\mathbf{0 . 0 0 1} ; \mathrm{D}_{2 \mathrm{cc}}: 84.4 \pm 4.3 \mathrm{~Gy}\right.$ $\& 76 \pm 5.2 \mathrm{~Gy}, \mathrm{P}=\mathbf{0 . 0 4 1})$ and Rectal ulcer $\left(\mathrm{D}_{0.1 \mathrm{cc}}: 104.5 \pm 18.5 \mathrm{~Gy} \& 89.9 \pm 17.6 \mathrm{~Gy}, \mathrm{P}=\mathbf{0 . 0 1 6} ; \mathrm{D}_{2 \mathrm{cc}}: 82 \pm\right.$ $7.7 \mathrm{~Gy} \& 75.9 \pm 4.8 \mathrm{~Gy}$

No difference was found in colon and urinary bladder events. Details given in Table 3 


\section{Dose effect analysis:}

Dose effect analysis was done using Probit regression model to find out ED5 and ED50 dose values. This analysis was restricted to only those dose volumes which showed statistical significant differences between Mild and Severe symptomatic groups. Results are summarized in Table 4. All dose-effect relationships were well defined, with $p$ dose $<0.05$. For proctitis with CTCAE Grade $\geq 3$ ED5 increases from 68.75 Gy to 79.97 Gy for $\mathrm{D}_{2 \mathrm{cc}}$ to $\mathrm{D}_{0.1 \mathrm{cc}}$. The ED50 increases from 71.75Gy to 82.9Gy.For Rectal haemorrhage with CTCAE Grade $\geq 3$ similarly ED 5 increases from 73.89 Gy to $92.57 \mathrm{~Gy}$. The ED50 increases from 87.29 Gy to $122.47 \mathrm{~Gy}$. For rectal ulcer with CTCAE Grade $\geq 3$ ED5 increases from 74.51Gy to 93.57Gy.Similarly ED50 increases from 99.38Gy to $150.63 \mathrm{~Gy}$.

Dose effect relationships are also illustrated graphically in Figure $1 \boldsymbol{\&} 2$.

On analyzing influence of 'brachytherapy fractionation' schedule on toxicity outcome no statistical difference was found (Table 5). There were dosimetric differences while comparing brachytherapy fractionation schedule which did not convert to toxicity parameter differences.

\section{Discussion}

In the treatment planning for cervical cancer brachytherapy, MRI- or CT-based 3D treatment planning is being increasingly used these days. To assess the dose to the rectum, 3D dose-volume parameters, including $\mathrm{D}_{0.1 \mathrm{cc}}, \mathrm{D}_{1 \mathrm{cc}}$, and $\mathrm{D}_{2 \mathrm{cc}}$ of the rectum calculated with $\mathrm{DVH}$, are recommended for recording and reporting ${ }^{[2,3]}$. Several investigators reported the relationship between these 3D dose-volume parameters and clinical outcomes. Georg P et al. calculated MRI-based dose-volume parameters and analyzed their correlation with clinical symptoms and recto-sigmoidoscopic findings. They reported that $\mathrm{D}_{2 \mathrm{cc}}$ dose was significantly higher in patients with clinical symptoms or moderate to severe mucosal changes than in those without clinico-pathological changes. They also found a significant dose effect correlation. They also calculated ED50 values for higher grade rectal morbidities ${ }^{[17]}$. Koom et al. compared CT-based dose-volume parameters with the findings of rectosigmoidoscopy, reporting that $\mathrm{D}_{0.1 \mathrm{cc}}, \mathrm{D}_{1 \mathrm{cc}}$ and $\mathrm{D}_{2 \mathrm{cc}}$ were significantly greater in patients with moderate to severe mucosal changes ${ }^{[22]}$.These data suggested that $3 \mathrm{D}$ dose-volume parameters may predict late rectal morbidity. However, long-term follow-up data on dose-volume parameters are quite limited. In case of bladder toxicity dose volume parameters are even more unclear. Researchers showed that CT and MRI-based scans at brachytherapy seem to be equally adequate for OAR DVH analysis ${ }^{[23]}$. At present, a large number of centers are practicing the MRI and CT based image guided brachytherapy planning. Standardization of this practice needs standard dose volume constrains guidelines. As the OARS are contoured using identical anatomical landmark a similar way in CT or MRI based planning, the same dose-volume constrains may be used in either case.In this present study attempts were made to establish dose effect correlation. The study was done in retro-prospective format of 206 patients with a mean follow up of 40 months (6 month - 72month).All patients not underwent endoscopic (cystoscopy/sigmoidiscopy) evaluation in fixed interval so a simpler grading system like CTCAE was used to evaluate morbidity pattern. Investigations were done only in symptomatic patients. Majority of colo-rectal occurred within first two years of follow up. Reported incidences of rectal bleeding are variable in literatures. In a study by Chun et al. incidence was $12.7 \%(\mathrm{n}=213)^{[29]}$.Other older studies reported an actuarial rate for rectal complications between $14 \%$ and $18 \%$ at 5 years ${ }^{[15,22,29]}$. But these studies ${ }^{[14,22,28,29]}$ were based on two dimensional point based planning. In our study over-all colo-rectal morbidity was seen in $21 \%$ patients which is little less than previous published report by Chen et al. $(\mathrm{n}=128,29 \%$ in 43 months median follow up $)^{[24]}$ but similar to other reports ${ }^{[14,22,28,29]}$. Georg $\mathrm{P}$ et al. found even higher incidence rate $(37 \%)$, but their study sample was very less $(n=35){ }^{[17]}$. In the present study only symptomatic patients underwent endoscopic evaluation which might lead underestimation of true incidence. Some newer studies with MRI based planning and reporting dose volume parameters are available now but also with variable results ${ }^{[30-33]}$.In a study by Potter $\mathrm{R}$ and colleagues with 145 patient incidence of recto-sigmoid and bladder late morbidities were $8.9 \%$ and $14.5 \%$ respectively ${ }^{[30]}$.

$\mathrm{D}_{2 \mathrm{cc}}$ dose difference of rectum (proctitis [82.6Gy/74.9Gy],rectal bleeding [80 Gy/76.2Gy] and ulcer [81.1Gy/75.4Gy]) is little higher than previous report by Georg P et al. ${ }^{[17]}$, but supporting the result of Chen et al. ${ }^{[24]}$. Mean values of DVH parameters except $\mathrm{D}_{\text {ICRU RECTAL }}$ point doses are significantly higher in Rectal CTCAE Grade $\geq 3$ versus CTCAE grade 1-2.(Table 3) with a mean of 81.5 Gy vs. 75.4 Gy. Due to the different dose definitions and different assessment scales used rectal morbidity and dose volume relationship showed a wide range of variability in the literatures. Chen et al. defined a cut off value of cumulative rectal BED 110Gy (i.e. EQD2=183.7 Gy) with highly variable dosing schedule ${ }^{[24]}$.Clark et al. defined BED above 125 Gy3 (i.e. EQD2 $=208.8 \mathrm{~Gy}$ ) as rectal reference dose, which is higher than reported doses in this study. But majority of the previous literature used point based dose reporting ${ }^{[14,15,17,22,24-27]}$. Table 6 showed comparative description of mean volume dose parameters reported in some recently published literatures. No consensus developed regarding reporting. Few recent studies with MRI based planning described dose-effect cut off values for optimization ${ }^{[30,37,38]}$. Georg P et al in their studies ${ }^{[17,37,38]}$ with MRI based adaptive ICBT recommended EQD2 
$\mathrm{D}_{2 \mathrm{cc}}$ cut off dose of rectum, sigmoid colon and bladder to be $70 \mathrm{~Gy}, 70 \mathrm{~Gy}$ and $90 \mathrm{~Gy}$ respectively. The ongoing EMBRACE study ${ }^{[1]}$ also gave emphasis over reporting small fixed dose volume in back ground of MRI based Image guided Brachytherapy (IGBT). Georg P et al. used ED values in dose reporting using linear quadratic equation based EQD2 values. However, similar to ongoing EMBRACE study ${ }^{[1]}$ and previous studies ${ }^{[17,37 \& 38]}$ our DVH results also showed precise dose -effect relationships. For rectal events (CTCAE Grade $\geq 3$ ) mean ED5 values and ED50 values were $72.4 \mathrm{~Gy}$ and $86.2 \mathrm{~Gy}$ respectively. Our results corroborates with previous studies $^{[17,30,34,35]}$.

In our dose/ volume analysis, we have attempted to document the dose to the rectum separating it from that of the recto sigmoid. Most previous studies summed the proctitis and enteritis symptoms together ${ }^{7,9,10, \text { and }}$ ${ }^{14]}$. But the risk is higher to the recto sigmoid part of the colon, and this, not uncommonly, passes unnoticed. AlBooz $\mathrm{H}$ et al. ${ }^{[39]}$ reported the recto-sigmoid colon as an unexpected OAR in a majority of cervix brachytherapy plans. Previous dose reporting of sigmoid colon were based on Point A or rectal dose parameters. In this study volume based dose parameters were determined. For sigmoid colon no significant difference exists for $\mathrm{D}_{0.1 \mathrm{ccc}}$ and $\mathrm{D}_{2 \mathrm{cc}}$ dose in Grade $\geq 3$ vs. Grade 1-2 analysis (Table3). This variation may be due to inter-fraction mobility of the upper part of the sigmoid colon. Dose values are little higher described by earlier experiments, most probably because of the same volumes not receiving the highest dose at each fraction $[1,17,30,37$, and 38$]$.

There may be a little underestimation of these real incidence parameters in bowel toxicities as asymptomatic patients were not evaluated endoscopically, due to retro-prospective nature of the study. There might be some cases of asymptomatic mucosal changes (i.e. telangiectasia) which were not included in the analysis.

Except for cystitis $(16.5 \%)$ haematuria was $<7 \%$ in incidence. In our study urinary tract morbidities especially cystitis and hematuria were not well correlated with dose volume parameters. Previous studies also failed to correlate bladder point dose with late bladder complications ${ }^{[10,40]}$ except for the study by Georg P et.al.$^{[38]}$. The International Commission on Radiation Units Report 38 system defined a bladder dose point; however, this point is not actual surrogate of the CT-based dose volume reporting ${ }^{[11]}$. In this study Viswanathan A. N. et al. reported mean bladder D2cc dose cutoff of $95 \mathrm{~Gy}^{[41]}$ Georg P et.al. in a cohort of 141 patients with MRI based ICBT showed a dose effect correlation of bladder morbidities with EQD2 $\mathrm{D}_{2 \mathrm{cc}}$ dose. $\mathrm{ED} 10$ values were $\geq 101 \mathrm{~Gy}$ for late urinary morbidities grade $\geq 2{ }^{[38]}$. More over urinary morbidities are better evaluated by scales based on subjective objective, quantitative, scoring systems like LENT/SOMA ${ }^{[41]}$. Due to retro-prospective nature of the study we did not used LENT/SOMA scales which may be another reason of not getting significant relationship in urinary morbidity irrespective of having large sample size.

\section{Conclusion}

This study was able to find out significant dose effect correlation between different volume doses and clinically evident $(\geq$ Grade 3 ) late morbidities in rectum. In rectal hemorrhage cutoff ED5 and ED50 doses were $92.6 \pm 5.8 \mathrm{~Gy} / 122.5 \pm 13 \mathrm{~Gy}$ (for $\mathrm{D}_{0.1 \mathrm{cc}}$ ), and $73.9 \pm 2.6 \mathrm{~Gy} / 87.3 \pm 3 \mathrm{~Gy}$ (for $\mathrm{D}_{2 \mathrm{cc}}$ ) respectively. For rectal ulcer these doses were $93.6 \pm 10.6 \mathrm{~Gy} / 150.6 \pm 20.8 \mathrm{~Gy}$, and $74.5 \pm 4.6 \mathrm{~Gy} / 99.4 \pm 9.2 \mathrm{~Gy}$ respectively. But for sigmoid colon and urinary bladder toxicities this correlation was not fully established.

[1]. www.embracestudy.dk last logged on $31^{\text {st }}$ August 2012

\section{Reference}

[2]. Haie-Meder C, Pötter R, Van Limbergen E, Briot E, De Brabandere M, Dimopoulos J, Dumas I, Hellebust TP, Kirisits C, Lang S, Muschitz S, Nevinson J, Nulens A, Petrow P, Wachter-Gerstner N; Gynaecological (GYN) GEC-ESTRO Working Group (I): Recommendations from Gynaecological (GYN) GEC ESTRO Working Group (I): concepts and terms in 3D image based 3D treatment planning in cervix cancer brachytherapy with emphasis on MRI assessment of GTV and CTV; Radiother Oncol 2005;74(3):235-45

[3]. Pötter R, Haie-Meder C, Van Limbergen E, Barillot I, De Brabandere M, Dimopoulos J, Dumas I, Erickson B, Lang S, Nulens A, Petrow P, Rownd J, Kirisits C;GEC ESTRO Working Group. Recommendations from gynaecological (GYN) GEC ESTRO working group (II): Concepts and terms in 3D image based treatment planning in cervix cancer brachytherapy-3D dose volume parameters and aspects of 3D image-based anatomy, radiation physics, radiobiology. Radiother Oncol 2006;78(1):67-77

[4]. Wachter-Gerstner N, Wachter S, Reinstadler E, Fellner C, Knocke TH, Wambersie A, Pötter R. Bladder and rectum dose defined from MRI based treatment planning for cervix cancer brachytherapy: comparison of dose-volume histograms for organ contours and organ wall, comparison with ICRU rectum and bladder reference point. Radiother Oncol 2003;68(3): 269-276

[5]. Olszewska AM, Saarnak AE, de Boer RW, van Bunningen BNFM, Steggerda MJ. Comparison of dose volume histograms and dose-wall histograms of the rectum of patients treated with intracavitary brachytherapy. Radiother Oncol 2001; 61(1):83-5.

[6]. Koom WS, Sohn DY, Kim JY, Shin K H, Yoon SM, Yoon M, Shin D, Park SY, Cho KH. Treatment planning for MRI assisted brachytherapy of gynecologic malignancies based on total dose constraints. Int J Radiat Oncol Biol Phys 2007; 68(5):1446-54

[7]. Barillot I, Horiot JC, Maingon P, Truc G, Chaplain G, Comte J, Brenier JP. Impact on treatment outcome and late effects of customized treatment planning in cervix carcinomas: baseline results to compare new strategies. Int J Radiat Oncol Biol Phys 2000; 48(1): 189-200.

[8]. Chen SW, Liang JA, Yang SN, Liu RT, Lin FJ. The prediction of late rectal complications following the treatment of uterine cervical cancer by high-dose-rate brachytherapy. Int J Radiat Oncol Biol Phys 2000; 47(4):955-61.

[9]. Eifel PJ, Thoms WW Jr, Smith TL, Morris M, Oswald MJ .The relationship between brachytherapy dose and outcome in patients with bulky endocervical tumors treated with radiation alone. Int J Radiat Oncol Biol Phys 1994; 28(1):113-8. 
[10]. Eifel PJ, Levenback C, Wharton T, Oswald MJ. Time course and incidence of late complications in patients treated with radiation therapy for FIGO stage Ib carcinoma of the uterine cervix. Int J Radiat Oncol Biol Phys 1995; 32(5):1289-300.

[11]. Fowler JF. The linear-quadratic formula and progress in fractionated radiotherapy. Br J Radiol 1989; 62(740):679-94.

[12]. Gerbaulet A, Pötter R, Haie-Meder C. Cervix Cancer. En: Gerbaulet A, Potter R, Mazeron JJ editors. GEC ESTRO handbook of brachytherapy, ESTRO Brussels; 2002. p. 301-63.

[13]. Kim TH, Choi J, Park SY, Lee SH, Lee KC, Yang DS ,Shin KH, Cho KH, Lim SH, Kim JY Dosimetric parameters that predict late rectal complications after curative radiotherapy in patients with uterine cervical carcinoma. Cancer 2005;104 (6):1304-11

[14]. Perez CA, Grigsby PW, Lockett MA, Chao KS, Williamson J. Radiation therapy morbidity in carcinoma of the uterine cervix: dosimetric and clinical correlation. Int J Radiat Oncol Biol Phys 1999; 44:855-66.

[15]. Sakata K, Nagakura H,Oouchi A, Someya M, Nakata K, Shido M ,Koito K, Sagae S, Kudo R, Hareyama M. High-dose-rate intracavitary brachytherapy: results of analyses of late rectal complications. Int J Radiat Oncol Biol Phys 2002; 54(5):1369-76.

[16]. Wang CJ, Leung SW, Chen HC, Sun LM, Fang FM, Changchien CC, Huang EY, Wu JM, Chen CC. High-dose-rate intracavitary brachytherapy (HDR-IC) in treatment of cervical carcinoma: 5-year results and implication of increased low-grade rectal complication on initiation of an HDR-IC fractionation scheme. Int J Radiat Oncol Biol Phys 1997; 38(2):391-8.

[17]. Georg P, Kirisits C ,Goldner G, Dorr W, Hammer J, Potzi R ,Berger D. Correlation of dose -volume parameters, endosopic and clinical rectal side effects in cancer cervix patients treated with definitive Radiotherapy including MRI based brachytherapy. Radiother Oncol 2009; 91:173-180

[18]. Visser AG, Symonds RP. Dose and volume specification for reporting gynaecological brachytherapy: time for a change. Radiother Oncol 2001; 58:1-4.

[19]. Ling CC, Schell MC, Working KR, Jentzsch, K., Harisiadis L., Carabell S., Rogers CC. CT-assisted assessment of bladder and rectum dose in gynecological implants. Int J Radiat Oncol Biol Phys 1987; 13:1577-82.

[20]. Kirisits C, Potter R, Lang S, Dimopoulos J, Wachter-Gerstner N, Georg D. Dose and volume parameters for MRI-based treatment planning in Intracavitary brachytherapy for cervical cancer. Int J Radiat Oncol Biol Phys 2005; 62:901-11.

[21]. Www.acrin.org/Portals/0/Administration/Regulatory/CTCAE_4.02_2009-09-15_QuickReference_5x7.pdf last logged on 10th August 2012

[22]. Koom WS, Sohn DK., Kim JY, Kim JW, Shin KH, Yoon SM, Kim DY, Yoon M, Shin D, Park SY, Cho KH. Computed tomography-based high-dose-rate intracavitary brachytherapy for uterine cervical cancer: Preliminary demonstration of correlation between dose-volume parameters and rectal mucosal changes observed by flexible sigmoidoscopy. Int J Radiat Oncol Biol Phys 2007,68(5): 1446-54.

[23]. Viswanathan AN, Dimopoulos J, Kirisits C, Berger D, Potter R. Computed tomography versus magnetic resonance imaging-based contouring in cervical cancer brachytherapy: results of a prospective trial and preliminary guidelines for standardized contours. Int $J$ Radiat Oncol Biol Phys 2007(2); 68:491-8.

[24]. Chen SW, Liang JA, Yang SN, Leu RT, Lin FJ. The prediction of late rectal complications following the treatment of uterine cervical cancer by high-dose-rate brachytherapy. Int J Radiat Oncol Biol Phys 2000;47(4):955-61.

[25]. Clark BG, Souhami L, Roman TN, Chappell R, Evans MD, Fowler JF. The prediction of late rectal complications in patients treated with high dose-rate brachytherapy for carcinoma of the cervix. Int J Radiat Oncol Biol Phys 1997;38(5):989-93.

[26]. Kim TH, Choi J, Park SY, Shin KH, Cho KH, Lim HS, Kim JY. Dosimetric parameters that predict late rectal complications after curative radiotherapy in patients with uterine cervical carcinoma. Cancer 2005;104(6):1304-11.

[27]. Pourquier H, Dubois JB, Delard R. Cancer of the uterine cervix: dosimetric guidelines for prevention of late rectal and rectosigmoid complications as a result of radiotherapeutic treatment. Int J Radiat Oncol Biol Phys 1982;8(11):1887-95.

[28]. Chun M, Kang S, Kil HJ, Oh YT, Sohn JH, Ryu HS. Rectal bleeding and its management after irradiation for uterine cervix cancer. Int J Radiat Oncol Biol Phys 2004;58(1):98-105.

[29]. Wang CJ, Leung SW, Chen HC, Sun LM, Fang FM, Changchien CC, Huang EY, Wu JM, Chen CC, Oh YT, Sohn JH, Ryu HS. High-dose-rate intracavitary brachytherapy (HDR-IC) in treatment of cervical carcinoma: 5-year results and implication of increased low-grade rectal complication on initiation of an HDR-IC fractionation scheme. Int J Radiat Oncol Biol Phys 1997;38(2):391-8.

[30]. Pötter R, Dimopoulos J, Georg P, Lang S, Waldhäusl C, Wachter-Gerstner N, Weitmann H, Reinthaller A, Knocke TH, Wachter $\mathrm{S}$, Kirisits C Clinical impact of MRI assisted dose volume adaptation and dose escalation in brachytherapy of locally advanced cervix cancer. Radiother Oncol. 2007 May;83(2):148-55

[31]. Haie-Meder C, Chargari C, Rey A, Dumas I, Morice P, Magné N. DVH parameters and outcome for patients with early-stage cervical cancer treated with preoperative MRI-based low dose rate brachytherapy followed by surgery. Radiother Oncol. 2009 Nov;93(2):316-21.

[32]. Chargari C, Magné N, Dumas I, Messai I, Vicenzi L, Gillion N, Morice P, Haie-Meder C. Physics Contributions and Clinical Outcome With 3D-MRI-Based Pulsed-Dose-Rate Intracavitary Brachytherapy in Cervical Cancer Patients. Int J Radiat Oncol Biol Phys 2009;74(1):133-9.

[33]. Lindegaard JC, Tanderup K, Nielsen SK, Haack S, Gelineck J. MRI-guided 3D optimization significantly improves DVH parameters of pulsed-dose-rate brachytherapy in locally advanced cervical cancer. Int J Radiat Oncol Biol Phys. 2008;71(3):756-64.

[34]. De Brabandere M, Mousa AG, Nulens A, Swinnen A, Van Limbergen E. Potential of dose optimisation in MRI-based PDR brachytherapy of cervix carcinoma. Radiother Oncol. 2008;88(2):217-26

[35]. Mahantshetty U, Swamidas J, Khanna N, Engineer R, Merchant NH, Shrivastava S Magnetic resonance image-based dose volume parameters and clinical outcome with high dose rate brachytherapy in cervical cancers--a validation of GYN GEC-ESTRO brachytherapy recommendations. Clin Oncol (R Coll Radiol). 2011;23(5):376-7

[36]. Haie-Meder C, Chargari C, Rey A, Dumas I, Morice P, Magné N. MRI-based low dose-rate brachytherapy experience in locally advanced cervical cancer patients initially treated by concomitant chemoradiotherapy. Radiother Oncol 2010;96(2):161-5

[37]. Georg P, Lang S, Dimopoulos JC, Dörr W, Sturdza AE, Berger D, Georg D, Kirisits C, Pötter R Dose-volume histogram parameters and late side effects in magnetic resonance image-guided adaptive cervical cancer brachytherapy. Int J Radiat Oncol Biol Phys. 2011;79(2):356-62

[38]. Georg P, Pötter R, Georg D, Lang S, Dimopoulos JC, Sturdza AE, Berger D, Kirisits C, Dörr W. Dose effect relationship for late side effects of the rectum and urinary bladder in magnetic resonance image-guided adaptive cervix cancer brachytherapy, Int $J$ Radiat Oncol Biol Phys. $2012 ; 82(2): 653-7$

[39]. Al-Booz H, Boiangiu I, Appleby H, French C, Coomber H, Humphery P, Cornes P. Sigmoid colon is an unexpected organ at risk in brachytherapy for cervix cancer. J Egypt Natl Canc Inst. 2006 ;18(2):156-60 
[40]. Pourquier H, Delard R, Achille E, Daly NJ, Horiot JC, Keiling R, Pigneux J, Rozan R, Schraub S, Vrousos C.A quantified approach to the analysis and prevention of urinary complications in radiotherapeutic treatment of cancer of the cervix. Int J Radiat Oncol Biol Phys. 1987;13(7):1025-33

[41]. Viswanathan AN, Yorke ED, Marks LB, Eifel PJ, Shipley WURadiation dose-volume effects of the urinary bladder. . Int J Radiat Oncol Biol Phys. 2010;76(3 Suppl):S116-2

Table legends:

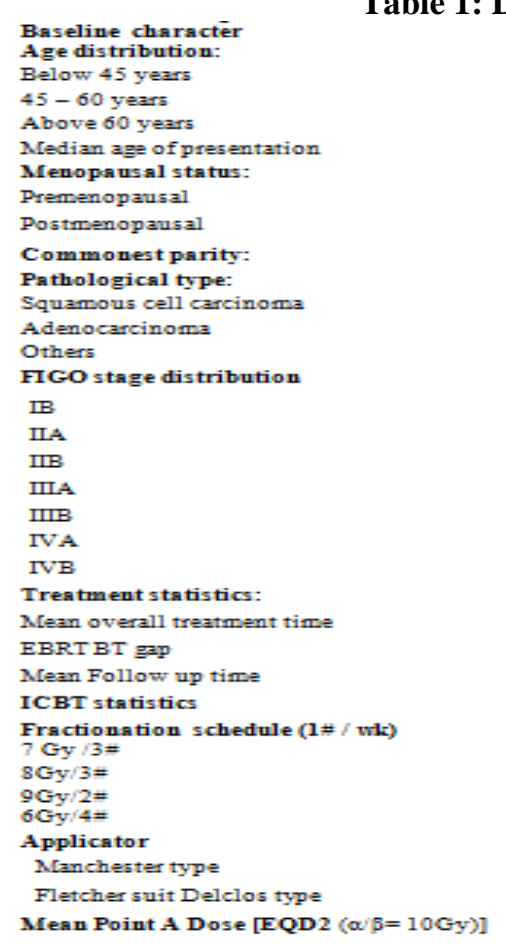

\section{Table 1: Descriptive statistics}

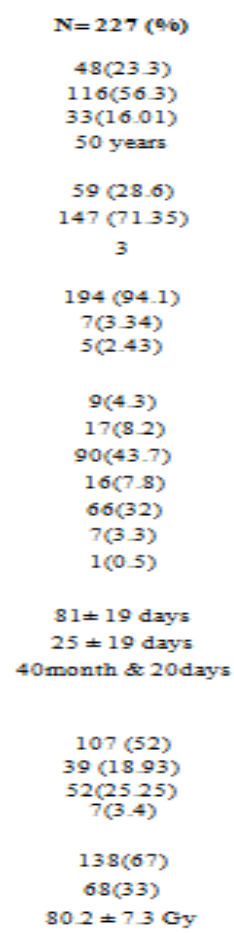

Table 2: Different fixed dose volumes of rectum, bladder and sigmoid colon calculated in EQD2.

\begin{tabular}{|c|c|c|c|c|c|}
\hline \multicolumn{2}{|c|}{ Parameters } & \multirow{2}{*}{$\begin{array}{c}\begin{array}{c}\text { Mean dose } \\
(\text { Gy) }\end{array} \\
90.6\end{array}$} & \multirow{2}{*}{$\begin{array}{c}\begin{array}{c}\text { Standard } \\
\text { deviation } \\
(\mathbf{G y})\end{array} \\
17.8\end{array}$} & \multirow{2}{*}{$\begin{array}{l}\text { Comparison } \\
\text { by Student } t \\
\text { test }(2 \text {-tailed p } \\
\text { value) }\end{array}$} & \multirow{2}{*}{$\begin{array}{c}\text { Median dos } \\
\text { (Gy) } \\
90\end{array}$} \\
\hline Rectum & $\mathrm{D}_{0.1 c c}$ & & & & \\
\hline & $\mathrm{D}_{2 ø c}$ & 76.2 & 16 & & 73.0 \\
\hline \multirow{5}{*}{ Bladder } & & & & 0.0016 & \\
\hline & $D_{\text {ICRU RECTAL }}$ & 72.1 & 8.4 & & 71.1 \\
\hline & $\mathrm{D}_{0.1 c c}$ & 105.8 & 24.5 & & 103.9 \\
\hline & $\mathrm{D}_{2 ø c}$ & 82.7 & 17.8 & & 90 \\
\hline & & & & $<0.0001$ & \\
\hline \multirow{3}{*}{ Sigmoid colon } & $\mathrm{D}_{\mathrm{ICRU}}$ BLADDER & 75.5 & 14.2 & & 75.6 \\
\hline & $\mathrm{D}_{0.1 c c}$ & 96 & 26.5 & & 92.6 \\
\hline & $\mathrm{D}_{2 c c}$ & 68.8 & 12.4 & & 67 \\
\hline
\end{tabular}


Table 3: Dose volume parameters in relation to clinical outcome in rectum, sigmoid colon \& bladder

\begin{tabular}{|c|c|c|c|c|}
\hline \multirow[b]{2}{*}{ Event } & \multicolumn{3}{|c|}{ according to CTCAE grading. } & \multirow[b]{2}{*}{$P$ value } \\
\hline & Volume Dose & $\begin{array}{l}\text { Grade 1-2 toxicity } \\
\text { (Mesn Dose in Gray) }\end{array}$ & $\begin{array}{l}\text { Grade 3-5 toxicity } \\
\text { (Mesn Dose in Gray) }\end{array}$ & \\
\hline \multirow[t]{3}{*}{ Proctitis } & $\mathbf{D}_{0,1 e z}$ & $89.9=17.5$ & $110.3 \pm 16.9$ & 0.003 \\
\hline & $\mathbf{D}_{2 e \varepsilon}$ & $75.8 \pm 46.8$ & $85.4 \pm 7.5$ & 0.037 \\
\hline & Dicke hectal & $71.9=8.4$ & $77.3=8.5$ & 0.148 \\
\hline \multirow{3}{*}{$\begin{array}{l}\text { Rectal } \\
\text { haemorrhage }\end{array}$} & $\mathbf{D}_{0.1 \mathrm{ee}}$ & $89.1=17.6$ & $106.1 \pm 13$ & $<0.001$ \\
\hline & $\mathbf{D}_{2 e x}$ & $76 \pm 5.2$ & $84.4 \pm 4.3$ & 0.041 \\
\hline & Dicke hectal & $71.9=7.9$ & $79=7.5$ & $<0.001$ \\
\hline \multirow[t]{3}{*}{ Rectal ulcer } & $\mathbf{D}_{0.1 \mathrm{er}}$ & $89.9=17.6$ & $104.5=18.5$ & 0.016 \\
\hline & $\mathbf{D}_{2 e z}$ & $75.9=4.8$ & $82=7.7$ & 0.015 \\
\hline & Dicke rectal & $72=8.5$ & $73.9=6.9$ & 0.148 \\
\hline \multirow{2}{*}{$\begin{array}{c}\text { Colon } \\
\text { Hemorrhage }\end{array}$} & $D_{0,1 e z}$ & $95.7 \pm 21.5$ & $128.8=6.9$ & 0.963 \\
\hline & $D_{2 e z}$ & $64.2=9.1$ & $69.1=12.5$ & 0.101 \\
\hline \multirow[t]{2}{*}{ Colon Ulcer } & $D_{0,1 e z}$ & $95.8=26.4$ & $126.6 \pm 6.8$ & 0.69 \\
\hline & $\mathbf{D}_{2 e \varepsilon}$ & $65.5=10$ & $68.85=12.4$ & 0.552 \\
\hline \multirow[t]{3}{*}{ Cystitis } & $\mathbf{D}_{0,1 \text { ex }}$ & $96.8=31.9$ & $105.9=24.4$ & 0.670 \\
\hline & $\mathbf{D}_{2 e z}$ & $80.2=15.8$ & $83.2=12.5$ & 0.778 \\
\hline & Dicke al.ADder & $66.6 \pm 8.30$ & $75.6 \pm 14.2$ & 0.187 \\
\hline \multirow[t]{3}{*}{ Hematuria } & $D_{0-1 e z}$ & $102.4=21.1$ & $105.9=24.6$ & 0.656 \\
\hline & $\mathbf{D}_{2 e z}$ & $83=12.4$ & $84.8=13.3$ & 0.731 \\
\hline & Dicke al.aDder & $72.3=11$ & $75.6=14.3$ & 0.438 \\
\hline
\end{tabular}

Table 4: Dose effect relationship in rectum for CTCAE Grade $\geq 3$

CTCAE Grade Dose ED5 (Gy) ED50 (Gy)

$\square 3$

Toxicity

Proctitis

Mean 95\% C.I.

P value

Upper Lower

Upper Lower
0.003
.037
0.001
.041
.001
015
0.963
0.101
0.69
.670
.778
.187
0.731
0.438 
“A Retrospective Study Of Correlation Between Reported Dose Volume Parameters For ...

Table 6: Comparative description of dose volume parameters with some recently published studies

\begin{tabular}{|c|c|c|c|c|c|c|}
\hline $\begin{array}{l}\text { Variables } \\
\text { EQD2 Dose } \\
\text { in Gy } \\
(\square / \square=3 G y)\end{array}$ & $\begin{array}{l}\text { U } \\
\text { Mahantshetty } \\
\text { et. al. }{ }^{[33]}\end{array}$ & \begin{tabular}{|l} 
Lindegaard \\
et. al. ${ }^{[33]}$
\end{tabular} & $\begin{array}{l}\text { Georg P et. } \\
\text { al. }^{[17]}\end{array}$ & $\begin{array}{l}\text { ChargariC } \\
\text { et. al. }{ }^{[32]}\end{array}$ & $\begin{array}{l}\text { De } \\
\text { Brabandere } \\
\text { et. al. }{ }^{[34]}\end{array}$ & $\begin{array}{l}\text { Current } \\
\text { study }\end{array}$ \\
\hline Rectal $D_{0.1 \mathrm{lec}}$ & $66.0 \pm 9.9$ & $74 \pm 9$ & $86 \pm 27$ & $70.6 \pm 11$ & $68 \pm 7$ & $90.4 \pm 18$ \\
\hline Rectal D $\mathrm{D}_{2 \mathrm{cc}}$ & $57.8 \pm 7.7$ & $67 \pm 6$ & $65 \pm 12$ & 60.5 & $62 \pm 4$ & $73.2 \pm 8$ \\
\hline $\mathrm{D}_{\text {ICRU RECTAL }}$ & $63.5 \pm 8.1$ & $71 \pm 7$ & $67 \pm 13$ & $67.3 \pm 8$ & $66 \pm 9$ & $72 \pm 8$ \\
\hline $\begin{array}{l}\text { Sigmoid } \\
\text { colon } \mathrm{D}_{0.1 \mathrm{lcc}}\end{array}$ & $109.4 \pm 45.2$ & $79 \pm 10$ & $84 \pm 32$ & $72.7 \pm 18$ & $82 \pm 13$ & $96.4 \pm 25.6$ \\
\hline $\begin{array}{l}\text { Sigmoid } \\
\text { colon } \mathrm{D}_{2 \mathrm{cc}}\end{array}$ & $74.6 \pm 19.6$ & $69 \pm 6$ & $62 \pm 12$ & $60.6 \pm 6$ & $68 \pm 7$ & $68.7 \pm 12.4$ \\
\hline $\begin{array}{l}\text { Urinary } \\
\text { Bladder } \\
\mathrm{D}_{0.1 \mathrm{ccc}}\end{array}$ & $139.1 \pm 54.7$ & $87.6 \pm 12$ & $162 \pm 75$ & $86 \pm 12$ & $100 \pm 12$ & $106 \pm 23.4$ \\
\hline $\begin{array}{l}\text { Urinary } \\
\text { Bladder } \\
\mathbf{D}_{2 c c}\end{array}$ & $93.4 \pm 24.6$ & $73 \pm 6$ & $95 \pm 2$ & $71.7 \pm 6$ & $82 \pm 6$ & $82.6 \pm 14$ \\
\hline $\begin{array}{l}\text { Urinary } \\
\text { Bladder } \\
\text { D }_{\text {ICRU }} \\
\text { BLADDER }\end{array}$ & $80.4 \pm 4.4$ & $67 \pm 8$ & $74 \pm 15$ & $63.7 \pm 9$ & $72 \pm 15$ & $75.8 \pm 13.1$ \\
\hline
\end{tabular}

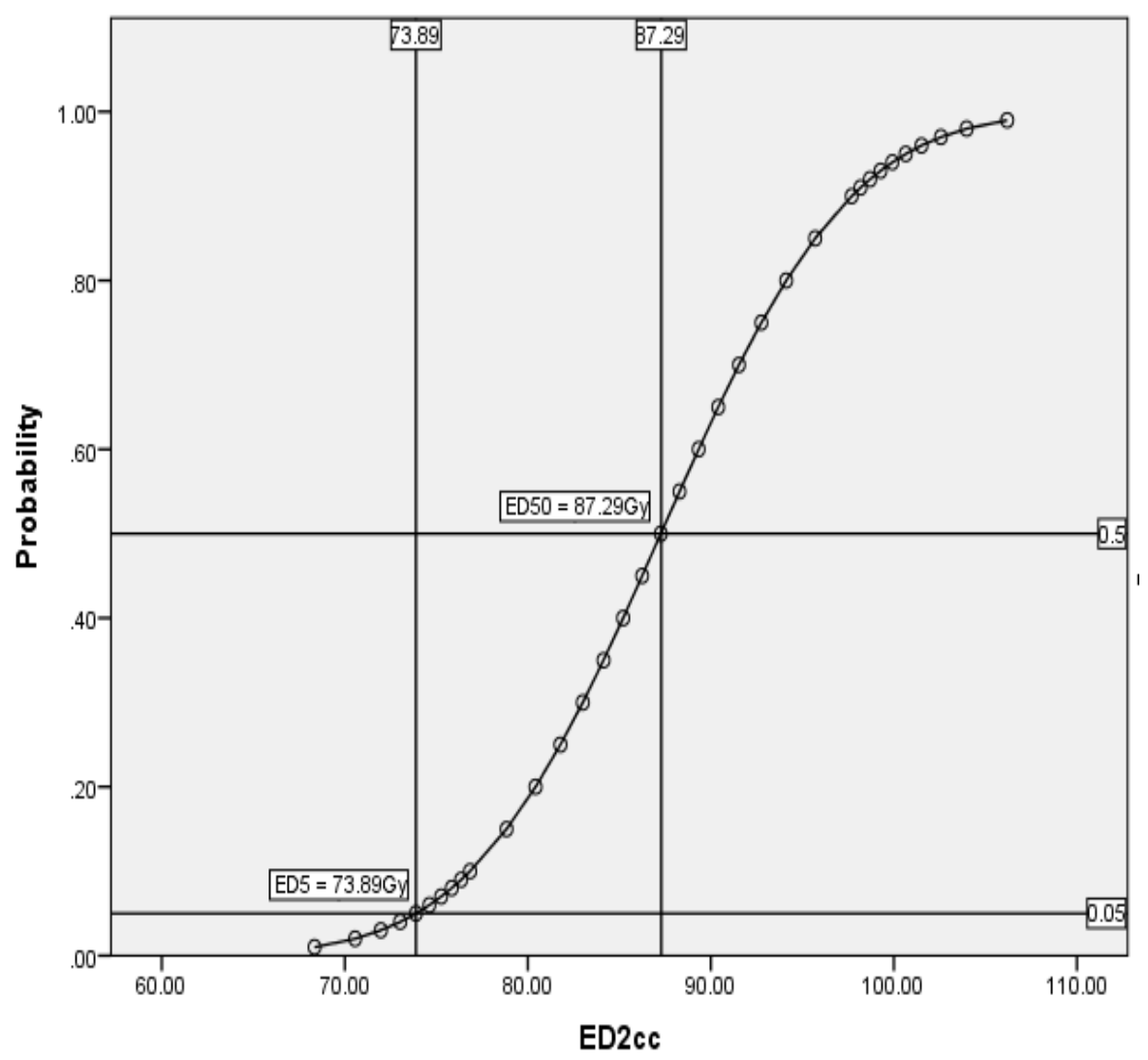

Correlation of ED2cc of rectum with probability of Rectal hemorrhage (CTCAE Grade $\geq 3$, in dose intervals of 10 Gv. Plotted on the basis of Probit Rearession analvsis

Figure.1 


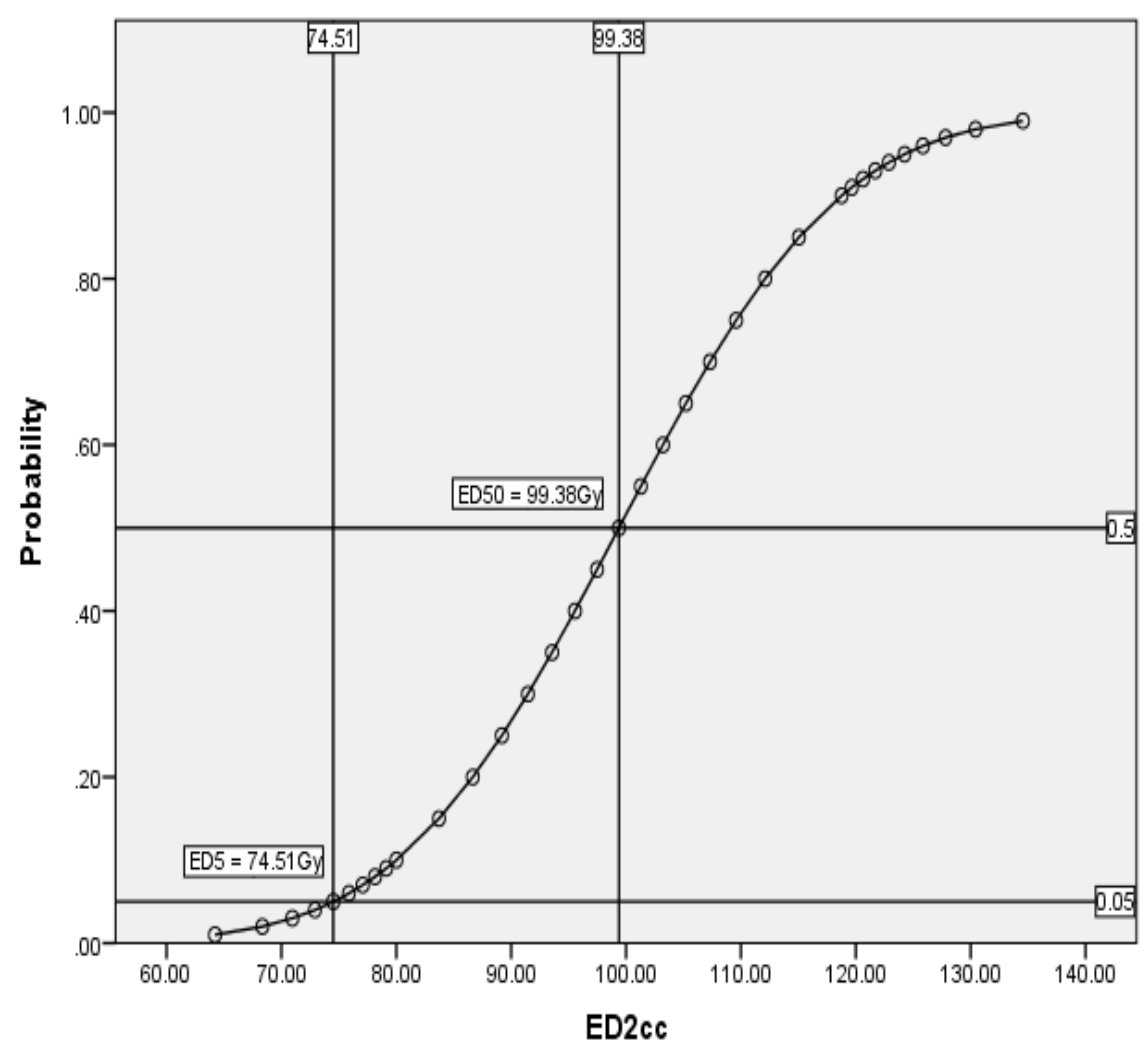

Correlation of ED2cc of rectum with probability of Rectal Ulcer (CTCAE Grade $\geq 3$ ) in dose intervals of $10 \mathrm{~Gy}$. Plotted on the basis of Probit Regression analysis

Figure.2 